\title{
A Method to Create a Process Reference Model Adapted to Heterogeneous Organizations
}

\author{
Geovanny Osorio ${ }^{1,2}$, Lorraine Trilling ${ }^{1}$, Thibaud Monteiro ${ }^{1}$, \\ Frédéric Albert ${ }^{3}$, and Pierre-Alain Millet ${ }^{1}$ \\ ${ }^{1}$ INSA de Lyon, DISP (laboratoire de Décision et d'Information des Systèmes de Production), \\ Bât. Jules Verne, 19 av. Jean Capelle, 69621 Villeurbanne, France \\ ${ }^{2}$ OVE, Euvre de village d'enfants, 19 Rue Marius Grosso, 69120 Vaulx-en-Velin \\ ${ }^{3}$ CERCLH \\ \{geovanny.osorio-montoya, lorraine.trilling, thibaud.monteiro, \\ pierre-alain.millet\}@insa-lyon.fr, frederic.albertacerclh.com
}

\begin{abstract}
In some cases there is a need to compare similarities between different process models. For example, given two organizations that offer products or services with similarities, we would like to know how much they differ from each other. This paper aims at defining a method to create a process reference model, which can be adapted to heterogeneous organizations. In order to construct this, we propose a method using BPMN language and based on the value chain approach. This process reference model issued from heterogeneous structures could enable managers to achieve a more comprehensive and unified vision of their organizations, and promote a coherent monitoring of activities. This work presents a unified method of communication between managers and organizations as well as throughout the structures comprising the organization. It provides a basis to establish an alignment of different structures in term of goals and business process following two axes.
\end{abstract}

Keywords: process reference model, value chain, BPMN, process approach.

\section{Introduction}

The constant evolution of business world lead organizations to change their perimeter (acquisition, separation, reorganization, etc.). Those changes require an aggregation of heterogeneous business process with a consistent management approach. So that, companies need to react by improving their knowledge about the process they performed as well as the new process to integrate. The fact of knowing the process and capitalize them by using a Process Reference Model (PRM) allows managers to cope with frequent and rapid changes in the business environment [1]. In this way companies need spontaneous solutions which can hardly be derived from wavering development [10]. Furthermore industrial and service sectors are pushed to the creation of process, which can respond to a customer demanding more and more customization of products and services [11].

Managers witnessed many attempts to improve the process-awareness in order to achieve a more comprehensive and unified vision of their sector, and to promote 
performance management organizations internally. A PRM should come from a button-up approach around the different types of organizations, in order to identify the variables that can affect the elements of the system as well as the specific activities of each type of organization [7]. If operational process models are unknown, structured top-down approaches, as conceptual methods, such as CIMOSA [19] or GRAI [20] cannot be useful.

The construction of a PRM comes from a collaborative and multidisciplinary work that seeks to develop a common language for operational, tactical and decisionmakers at all levels. The combination of a PRM with management tools like balanced scorecards can play a crucial role in the development and structuring of the common vision, as experience shows [5-6].

The aim of this paper is to propose a method to obtain a PRM. This method is illustrated by an application in the socio-medical sector, but could be used in other fields. This article is divided into 5 parts. Section 2 highlights the necessity for the construction of a PRM, supported by a literature review. Section 3 explains the proposed method for the construction of a PRM. Section 4 gives the application of the proposed approach in socio-medical sector, which requires such reference model before being able to monitor activities. Finally, section 5 provides a conclusion and gives some perspectives on this research.

\section{Related Works}

The emergence of computer technology and the increase in data flows in the last two decades leads the organizations to improve its knowledge about the processes they perform using information systems. Early examples of these, seek to organize a process as a defined sequence of tasks. Such systems were called Workflow management systems (WFM) $[14,15]$. At the present, these systems have evolved with a greater range allowing the processes simulation and monitoring of the activities [4, 16, 17]. These ones are now called Business Process Management (BPM). Either the WFM or BPM, both systems aim to support operational processes.

Process modeling allows structuring and visually representing activities of an organization. It facilitates communication around the processes between different actors and enhance the understanding of the functioning of the company [7]. The creation of a PRM for an organization raises several issues. It involves (1) the gathering and analysis of currents models, (2) a field study in a sample of different structures to complete the analyzed information, (3) a modeling of performed activities in each structure using a common language, (4) a comparison of the modelled activities with good professional practices and the respect of legal standards, (5) an identification of the main similarities and differences to retain the models or model's fragments [8]. Thus, using these fragments, we must create a PRM in which all the fragments can fit while avoiding duplication [9].

Indeed, there are several invariants in the set of structures that led to the institutionalization of successful process to be re-used. In this context, experts have developed generic models allowing a logical progression for resolution of problems. Our aim is to create a model that subsumes a collection of process models from each structure (representing variants of the same underlying process) with the aim of replacing the variants 
with the merged model. The challenge here is not the modeling of processes from each structure, but the creation of a method to integrate different activities from a set of heterogeneous structures which is not specifically proposed in literature.

\section{Method for Construction of the Process Reference Model}

In order to achieve one PRM which can be transposable to different kind of organizations, we proposed a method divided in three main steps Fig 1. The first step aims to collect information in the field in order to identify activities carried out in different organizations and the manner in which these are performed. The second step seeks to establish the working perimeter conditioned by good professional practice and the respect of legal standards in the field of the application, which should be integrated in the PRM. Finally, the goal of the third step is to compare and combine different existing models using a set of aggregation and transformation operators, which would lead to construct an activities reference model matching with all types of organizations and taking into account existing references.

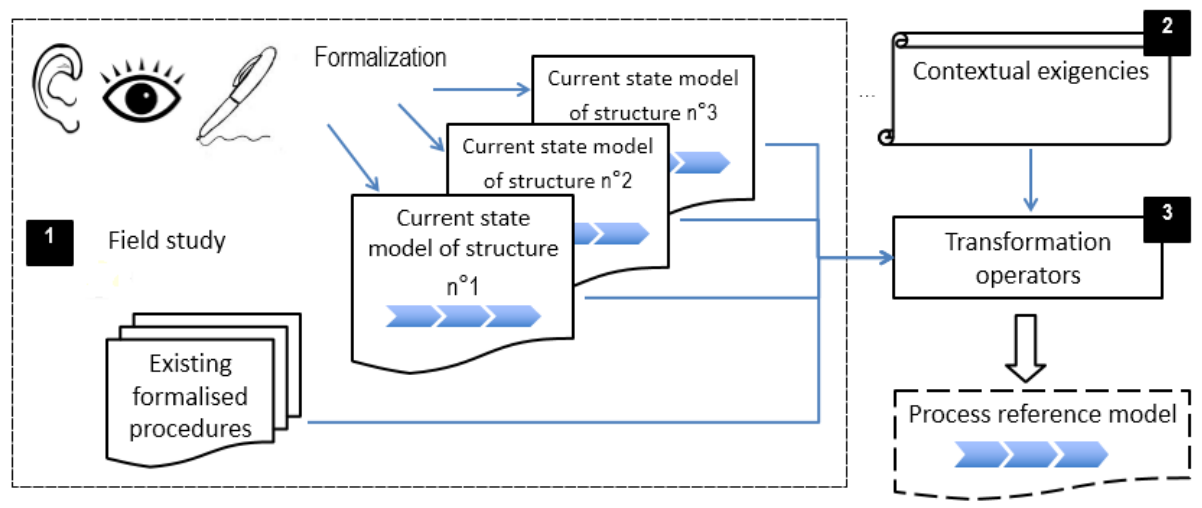

Fig. 1. Proposed method to create a process reference model

\subsection{Current State Modelling}

To gather the necessary information enhancing the knowledge of production flows and activities carried out by the organizations, it is necessary (i) to use reliable sources describing the process, as existing official procedures (flowcharts respecting the legal framework and referential quality) and (ii) to collect information from people in the field (information extracted from interviews with several professionals in different structures of the organization).

This set of information should be formalized for each structure using a simple and universal language allowing the modeling of business processes easily readable and understandable for all staff involved. We use a process map inspired by the Value Chain developed by Michael Porter [2] and a process approach [3] structuring activities around the three types of processes: Value-added process, Control process, and Support process. 
To detail the processes as a flowchart of activities, we used the BPMN [15]. This language provides an easy notation that is intuitive for both technical users and business users. The Fig .2 illustrates the structure of the map and the principle of the processes decomposition (level 0 ) in an ordered organization of activities (level 1).

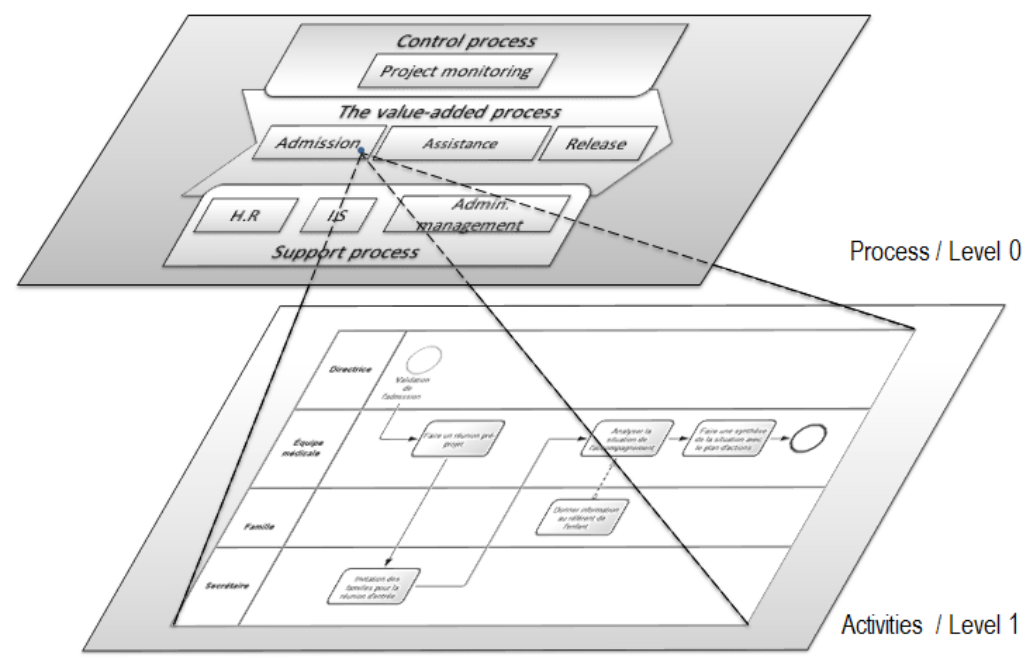

Fig. 2. Map of business processes and process detail with BPMN

\subsection{Contextual Exigencies for a Process Reference Model}

Even if professionals consider that modeled processes match to the processes performed in their structures, the modeling of these must drive to an assessment of activities. This is necessary to evaluate whether these activities actually correspond to good professional practice and assess if they are in accordance with the regulations of the sector. The formalization of existing practices helps to highlight deviations from best practices and conducts to the creation of a shared model.

To perform this step, we used a working group (composed by professionals of each modeled structure, and the deputy general director) with the aim to present the different practices carried out. This allows reaching a consensus on the practices to be used in the PRM as well as the way to name each of them.

\subsection{Operators for the Construction of a Process Reference Model}

The characteristic of a reference model is that it enables an entity or structure to recognize itself within a common framework which is not however specifically designed for this entity. The PRM is issued from current state models compared to the contextual exigencies. This construction has to minimize the gap between starting models and the final one. A particular attention is paid to integrate the constraints imposed by the consensus around contextual exigencies (best practices, legal standards...). 
Furthermore, it is necessary to define the granularity level of the PRM; this one would be able to fit the different structures, while including specificities at a finer level of detail. It has to be able to report a board spectrum of activities. The PRM has to be precise enough to clearly describe the activities carried out in each structure which are inherently heterogeneous.

The construction of a PRM allows revealing similarities in the activities of each structure. However, the knowledge of best practices to improve is not acquired. So that, any improvement in the performance necessarily involves a practice's identification [12].

Models must be built by the same team, in order to have the same interpretation. Hence, process models should be built one after another. Generally, the designer of a PRM might not foresee all configuration options that are required in actual practice. Hence, additional model adaptations might become necessary when configuring a particular process variant [13]. In order to construct the PRM we propose to use specific operators. Those operators translate an analysis of the similarities and differences between starting model (Fig.3.)

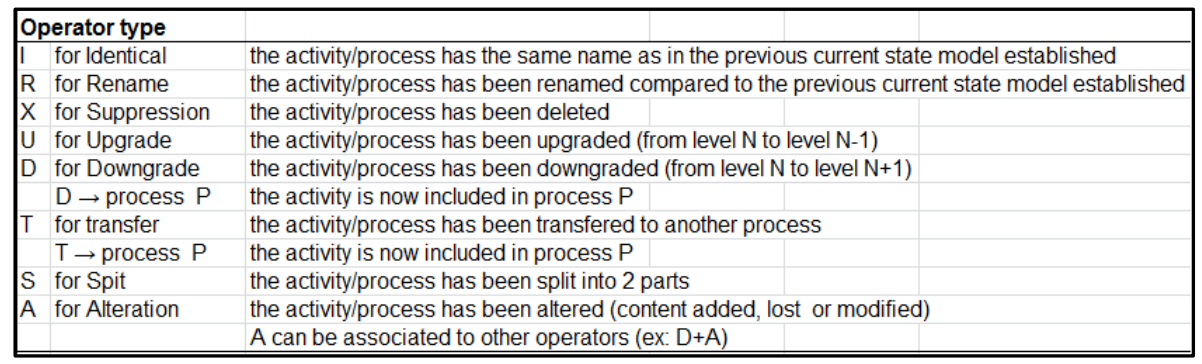

Fig. 3. Operators for the construction of the process reference model

\section{$4 \quad$ Implementation and Results}

\subsection{Field of Application}

In order to validate the proposed method, we conducted a work in an important medicosocial foundation from Rhône-Alpes Region named OVE. Medico-social sector witnessed many attempts to achieve a more comprehensive and unified vision, and to promote performance management structures internally. Furthermore, on a work carried out by the National agency to support the performance (ANAP) express that "the medico-social structures produce little or no data about his performed activities" [18]. This sector is a whole wide range dedicated to the support of vulnerable people who are the users of the system (people in precarious situations, children or troubled teens, disabled persons and the elderly). Due to the heterogeneity of the sector and the large number of structures (around 8200 in France) this research must lead to a PRM, which takes into account several structures for centralized decisions. 


\subsection{Results}

Using seven type of structures, we constructed seven different models taking into account the specific characteristics of activities carried out in each type of structure, afterwards, we classified these activities according to the three type processes: valueadded, support and control processes. This model "all terrain" has allowed to adopt a common language, shared from top management to professionals, for naming all the activities performed by the structures.

Using the models process divided in two levels (Fig. 2) and the specific operators (Fig. 3), the construction of a PRM is a gradual process of comparison between the different starting models (Fig. 4).

The first reference model serves to identify the first activities as well as a first "sketch" of a process model. With the next models, we created a model that subsumes a collection of process models (typically representing variants of the same underlying process) with the aim of replacing the variants with the merged model. Then activities were reorganized into a common process that can be adaptable to the set of organizations using the operators proposed. Besides serving as a state of the art and show a first field- work of the functioning of the organizations, this process allows to identify the specific activities performed, as well as activities that do not correspond to good professional practice or that are not supported in the policies of the foundation. Making this comparison Fig. 4, we can observe that after the fifth modeled structure, specific processes found begin to decrease.

\begin{tabular}{|c|c|c|c|c|c|c|c|c|c|c|c|}
\hline \multirow{2}{*}{ Code } & \multirow{2}{*}{$\begin{array}{l}\text { Process name } \\
\text { (First current state model) }\end{array}$} & \multicolumn{7}{|c|}{ Heterogeneous Structures } & \multirow{2}{*}{ PRM } & \multirow{2}{*}{$\begin{array}{l}\text { Process name } \\
\text { (Final Process reference model) }\end{array}$} & \\
\hline & & 1 & 2 & $\mathbf{3}$ & 4 & 5 & 6 & 7 & & & \\
\hline VA1 & Admission to the user & $\mathrm{I}$ & $\mathrm{I}$ & 1 & 1 & 1 & 1 & 1 & I & & VA1 \\
\hline VA2 & Preparation of the assistance & 1 & & $\mathbf{R}$ & & $\mathrm{R}$ & 1 & $\mathrm{R}$ & R & Design and updating the PIA & VA2 \\
\hline VA3 & User assistance & 1 & R & 1 & 1 & 1 & 1 & $\mathrm{R}$ & 1 & User assistance & VA3 \\
\hline VA4 & Preparing the user release & 1 & I & 1 & 1 & 1 & $\mathrm{I}$ & 1 & I & Preparing the user release & VA4 \\
\hline VA5 & Post-monitoring assistance & $\mathrm{I}$ & & & & & & $\mathrm{R}$ & D $>$ VA4 & & \\
\hline VAG & Collective meeting for new users & & 1 & & & 1 & & & D $>$ VA1 & & \\
\hline VA7 & Hosting & & I & & & 1 & I & & 1 & Hosting & VA7 \\
\hline VA8 & Speech therapist record & & & & & & & & $D->V A 2$ & & \\
\hline VA9 & Assistance outside the structure & & & & & & 1 & & $D->V A 3$ & & \\
\hline P1 & GESTUSA 2 & 1 & 1 & 1 & 1 & 1 & $\mathrm{I}$ & 1 & 1 & GESTUSA 2 & P1 \\
\hline P2 & Risk Management & 1 & 1 & & 1 & 1 & 1 & 1 & I & Risk Management & P2 \\
\hline P3 & Satisfaction survey & 1 & I & & 1 & 1 & 1 & & D $>$ P12 & & \\
\hline P4 & Steering of the assistance project & I & 1 & 1 & 1 & 1 & 1 & 1 & 1 & Steering of the assistance project & P4 \\
\hline P5 & Tactical monitoring of project assistance & I & $\mathrm{I}$ & $\mathrm{I}$ & 1 & 1 & $\mathrm{I}$ & 1 & $D \rightarrow 14$ & & \\
\hline P6 & Operationnal monitoring of project assistance & 1 & 1 & 1 & 1 & 1 & 1 & 1 & I & Operationnal monitoring of project assistance & P6 \\
\hline P7 & Professional Education & 1 & & & $\mathrm{R}$ & & 1 & & R & Education action & P7 \\
\hline P8 & Advice and opinions with other structures & I & $\mathbf{R}$ & $\mathbf{R}$ & & $\mathbf{R}$ & $\mathrm{R}$ & & R & Animation of network partnerships & P8 \\
\hline pg & Achievement of firsts school days & & 1 & & $\mathbf{R}$ & $\mathrm{R}$ & $\mathrm{R}$ & $\mathbf{R}$ & $\mathrm{x}$ & & \\
\hline P10 & Commission regulation with the MDPH & & 1 & 1 & & 1 & $\mathbf{I}$ & 1 & D-> VA1 & & \\
\hline P11 & Organization of extracurricular activities & & 1 & 1 & & 1 & & & D $>$ VA3 & & \\
\hline P12 & Meeting to evaluate the evolution of the structure & & I & 1 & & 1 & $\mathrm{I}$ & & R & Quality approach & P12 \\
\hline P13 & Management of post-admission period & & & 1 & & & & & $D \rightarrow V A 2$ & & \\
\hline P14 & Monitoring of user professional assistance & & & 1 & & & & & $D+A->V A 3$ & & \\
\hline P15 & Monitoring of user social assistance & & & 1 & & & & & $D+A->V A 3$ & & \\
\hline P16 & Speech therapist record & & & & 1 & & & & D $>$ VA2 & & \\
\hline P17 & Commission studies of priority candidates & & & & & 1 & & & $D+A->V A 1$ & & \\
\hline
\end{tabular}

Fig. 4. Gradual process of comparison between the different starting models

This means that the model begins to converge and all the identified processes can describe almost entirely the process of the last two structures. This is however not sufficient for the construction of a PRM, which requires the continuous support of the general direction. This last is necessary to arbitrate the processes to be integrated into the reference model, as well as the flow charts of process information and samples of good practices. This PRM represents the starting point for activity monitoring and 
performance assessment while providing a unified method of communication throughout the structures of the foundation in order to establish an alignment in the set structures goals.

\subsection{Validation of Process Reference Model Using a Software for Activities Monitoring: Gestactiv}

In order to check whether the reference model is adapted to a set of heterogeneous structures we proposed a software to collect information related to the activities (formalized in the process reference model) that are performed in all structures. This survey information provided by this software enables us to confront the selected PRM with the activities performed by the set of structures.

The evaluation of the PRM was based in a real size experimentation. Nine "pilot" structures with almost 150 professionals and 350 users over a period of three months have entered their activities in the system according to the reference model. This has led to validate the ability of constructed PRM to reflect the day-to-day of professional activities. With the prospect of a generalization in 2015 to 65 structures from OVE Foundation, the PRM has proved robustness with respect to the reality of the implementation in the field activities. This is reflected by the significant integration of the tool in professional routines. The main indicators were the capture rate of foresight activities (43\% of activities scheduled at least 3 days in advance), the degree of validation following the completion of them (95\%) and the rate of implication of professionals to capture the positive returns.

\section{Conclusions}

The bottom up approach facing with contextual exigencies meets the need for a better knowledge about how an organization works. This approach provides a structured representation of the activities carried out within structures on which an activity monitoring tool is based. An experiment in the medico-social sector has validated the proposed approach.

For future works, the measures collected from the combination of process reference activities and monitoring tool will offer the possibility to answer questions at the operational level related to the user assistance and the consumption of resources. These measures establish a basis on which improvements can be developed: Balanced Scorecard (BSC), tools and methods to assist in the management organizations works. This approach combined with a tool allowing the lift up of the activities will translate strategy into operational action plans at all levels of the organization by providing information on the performance of each entity, useful to control them. These examples could open paths to numerous development opportunities in this sector. 


\section{References}

1. van der Aalst, W.M.P.: Process-aware information systems: Lessons to be learned from process mining. In: Jensen, K., van der Aalst, W.M.P. (eds.) Transactions on Petri Nets and Other Models of Concurrency II. LNCS, vol. 5460, pp. 1-26. Springer, Heidelberg (2009)

2. Porter, M.E.: Competitive advantage: Creating and sustaining superior performance. Simon and Schuster Ed. (2011)

3. Brandenburg, H., Wojtyna, J.P.: L'approche processus. Eyrolles Ed. (2006)

4. Wohed, P., van der Aalst, W.M.P., Dumas, M., ter Hofstede, A.H.M., Russell, N.: On the Suitability of BPMN for Business Process Modelling. In: Dustdar, S., Fiadeiro, J.L., Sheth, A.P. (eds.) BPM 2006. LNCS, vol. 4102, pp. 161-176. Springer, Heidelberg (2006)

5. Kaplan, R., Norton, D.: Transforming the Balanced Scorecard from Performance Measurement to Strategic Management: Part I. Accounting Horizons 15(1), 87-104 (2001)

6. Martello, M., Watson, J.G., Fischer, M.J.: Implementing a Balanced Scorecard in a not for profit organization. Journal of Business \& Economics Research 6, 9 (2011)

7. Ulrich, F.: Evaluation of reference models. Reference Modeling for Business Systems Analysis, 118-140 (2007)

8. La Rosa, M., Dumas, M., Uba, R., Dijkman, R.: Business process model merging: an approach to business process consolidation. ACM Transactions on Software Engineering and Methodology (TOSEM) 22(2) (2013)

9. Fiorèse, S., Meinadier, J.P.: Découvrir et comprendre l'ingénierie systéme. Cépadués Ed. (2012)

10. Mintzberg, H.: In a Dynamic Business World, Phrases Such as 'Strategic Planning', 'Marketing Planning' or 'Change Management' Are Oxymoronic! (2011) (retrieved 11)

11. Hau, L.L., Feitzinger, E., Billington, C.: Getting ahead of your competition through design for mass customization. Target 13(2), 8-17 (1997)

12. Jacques, J.: Amélioration de la performance industrielle à partir d'un processus Référent. $\mathrm{PhD}$ Thesis of Savoie university (2006)

13. Manfred, R., Weber, B.: Enabling flexibility in process-aware information systems: challenges, methods, technologies. Springer Ed. (2012)

14. Van der Aalst, W.M., Van Hee, K.M.: Workflow Management: Models, Methods, and Systems. MIT Press (2004)

15. Jablonski, S., Bussler, C.: Workflow Management: Modeling Concepts, Architecture, and Implementation. International Thomson Computer Press Ed. (1996)

16. Wynn, M.T., Dumas, M., Fidge, C.J., ter Hofstede, A.H.M., van der Aalst, W.M.P.: Business process simulation for operational decision support. In: ter Hofstede, A.H.M., Benatallah, B., Paik, H.-Y. (eds.) BPM Workshops 2007. LNCS, vol. 4928, pp. 66-77. Springer, Heidelberg (2008)

17. Rozinat, A., Wynn, M.T., van der Aalst, W.M.P., ter Hofstede, A.H.M., Fidge, C.J.: Workflow simulation for operational decision support using design, historic and state information. In: Dumas, M., Reichert, M., Shan, M.-C. (eds.) BPM 2008. LNCS, vol. 5240, pp. 196-211. Springer, Heidelberg (2008)

18. ANAP, Piloter la performance dans le secteur médico-social: Expérimentation d'un tableau de bord de pilotage (2011), http: / / www . anap. fr

19. Vernadat, F.B.: Enterprise modelling and integration: principles and applications. Chapman \& Hall, London (1996)

20. Kromm, H., Ducq, Y.: Reference decision models in the medico-social service sector. In: Emmanouilidis, C., Taisch, M., Kiritsis, D. (eds.) Advances in Production Management Systems, Part II. IFIP AICT, vol. 398, pp. 422-429. Springer, Heidelberg (2013) 